\title{
Teoria Crítica e Democracia Deliberativa: diálogos instáveis
}

\begin{tabular}{c}
\hline \hline Ricardo Fabrino Mendonça \\
Departamento de Ciência Política \\
Universidade Federal de Minas Gerais \\
\hline \hline
\end{tabular}

\begin{abstract}
Resumo: Este artigo discute a relação entre as abordagens deliberacionistas de democracia e a Teoria Crítica. Para tanto, apresentam-se três argumentos que sugerem uma dissociação entre os dois corpos teóricos: 1) A deliberação reforça quadros de dominação existentes; 2) A deliberação conformou-se às instituições liberais em voga; e 3) A guinada empírica dos estudos deliberativos aproximaram-nos da teoria tradicional. A partir desses argumentos, o texto ressalta a existência de um diálogo
\end{abstract} instável entre a abordagem deliberativa e o legado frankfurtiano.

Palavras-chave: Democracia Deliberativa; Teoria Democrática; Teoria Crítica; Escola de Frankfurt; Filosofia Política

Abstract: This paper discuss the relationship between deliberative approaches of democracy and critical theory. In order to do so, it presents three arguments that suggest a deep distinction between these two theoretical traditions: 1) Deliberation reinforces existent forms of domination; 2) Deliberation has accepted the existent democratic liberal institutions; 3) The empirical turn of deliberative literature has brought it closer to traditional theory. Based on these arguments, the article highlights the existence of an instable dialogue between the deliberative approach and the Frankfurtian legacy.

Keywords: Deliberative Democracy; Democratic Theory; Critical Theory; Frankfurt School; Political Philosophy 


\section{Introdução}

É comum associar o modelo deliberacionista de democracia ao legado político e filosófico da Teoria Crítica. Muitos deliberacionistas tendem a se pensar como os continuadores do legado de Frankfurt, buscando elaborar uma teoria que dê conta das aspirações emancipatórias que alicerçam a escola. Tal associação está ligada a, basicamente, três fatores: 1) o forte diálogo com as noções habermasianas de racionalidade comunicativa e esfera pública; 2) o caráter normativo do modelo; e 3) a crítica à teoria da escolha racional de origem liberal. Contestando a redução da política à luta de indivíduos autointeressados, os deliberacionistas alegam propor um viés crítico, que aposta na comunicação como modo de fortalecer a autonomia dos sujeitos e a construção colaborativa de decisões.

O presente artigo busca discutir se essa vinculação automática entre deliberação e Teoria Crítica faz sentido. A motivação para sua elaboração nasceu nos debates do Grupo de Trabalho (GT) "Comunicação e Política" do XIX Encontro Anual da Compós (2010). Naquela ocasião, advoguei uma abordagem ampliada de deliberação, defendendo sua fidelidade ao legado crítico. Isso levou Luís Felipe Miguel a sugerir a inadequação de meu argumento. O pesquisador indagou se a ampliação do conceito de deliberação não o destituía de todo teor crítico, reforçando a já sistemática negligência dos deliberacionistas à questão do poder. Na opinião do autor, o modelo deliberativo teria se acomodado ao liberalismo.

Minha réplica a Miguel buscou recusar a associação imediata entre a democracia deliberativa e as abordagens liberais. Argumentei que havia distinções fundamentais em termos de princípios e premissas. A pergunta, contudo, não foi plenamente respondida, e este artigo busca refletir, com mais vagar, sobre a mencionada crítica.

O artigo está dividido em três seções. A primeira delas realiza uma breve discussão sobre as raízes, definições e objetivos da tradição crítica. A segunda seção explora três argumentos que indicariam uma dissociação entre o modelo deliberacionista e a Teoria Crítica: 1) A deliberação reforça a ordem existente; 2) A deliberação conformou-se às instituições liberais; e 3) A guinada empírica dos estudos deliberacionistas aproximou-os da teoria tradicional. Por fim, na terceira seção, pontuam-se aproximações e distanciamentos na tensa relação entre o modelo deliberacionista e o legado crítico.

Meu argumento é o de que existe um diálogo instável entre a abordagem deliberativa e o legado frankfurtiano. É possível estabelecer muitos pontos de contato entre ambas as tradições, sendo incorreto afirmar que o modelo deliberacionista liberalizou-se por completo. Por outro lado, seria igualmente inadequado supor uma continuidade absoluta entre as abordagens analisadas. Há hiatos significativos entre elas, os quais passam não apenas pelos ideais políticos defendidos, mas também pelos princípios metodológicos adotados. Sustento que um diálogo mais estável entre tais tradições seria extremamente profícuo, contribuindo, inclusive, para a correção recíproca de aspectos subexplorados em cada uma delas.

\footnotetext{
1 Uma versão deste artigo foi apresentada ao Grupo de Trabalho (GT) "Comunicação e Política" do XX Encontro da Compós, na Universidade Federal do Rio Grande do Sul, Porto Alegre (Brasil), de 14 a 17 de junho de 2011 . As pesquisas que embasam este artigo receberam apoio da PRPq (Universidade Federal de Minas Gerais), do CNPq (Processo: 476130/2011.5) e da Fapemig (Edital 01/2011/Processo: SHA . APQ.00544-11) A essas instâncias, sou grato pelo financiamento. Também sou grato a Victor Guimarães, Débora Bráulio e Jonas Guerzoni pelos vários e inspiradores debates sobre Teoria Crítica.
} 


\section{Teoria Crítica: raízes, definições e objetivos}

A Teoria Crítica é uma tradição de pensamento que "não se limita a descrever o funcionamento da sociedade, mas pretende compreendê-la à luz de uma emancipação ao mesmo tempo possível e bloqueada pela lógica própria da organização social vigente" (NOBRE, 2003, p. 9). O viés apresenta-se, assim, como elemento de uma práxis social que busca subverter experiências opressivas, estimulando sua transformação estrutural (WIGGERSHAUS, 2002). Criticando os esforços teóricos descolados da realidade social, essa vertente de pensamento protesta, filosoficamente, contra a ordem naturalizada, defendendo a autodeterminação humana. Como sintetiza Carnaúba: "teoria crítica envolve diagnóstico do tempo presente, orientação para a emancipação e comportamento crítico" (CARNAÚBA, 2010, p. 196).

Embora existam diferentes correntes contemporâneas de pensamento crítico, as raízes da abordagem aqui enfocada encontram-se na Alemanha da década de 1920, quando um grupo de pesquisadores de orientação marxista fundou o Instituto de Pesquisa Social de Frankfurt. Associado à universidade da cidade, o Instituto surgiu no conturbado contexto da República de Weimar, em que tanto a direita como a esquerda alemãs se rearticulavam diante da iminência de uma grande transformação. Nesse cenário, o grupo se propunha a agir por meio da prática teórica, superando o dualismo entre práxis e teorią. Não caberia, aqui, mapear as proposições e contribuições de diferentes pesquisadores do Instituto. Para nossos objetivos, basta captar as premissas que alicerçam o legado de Frankfurt, as quais foram explicitamente delineadas depois que Horkheimer assumiu sua direção em 1931. Conduzindo o grupo por um período de duas décadas, o filósofo estabeleceu as diretrizes acadêmicas (e pessoais) do Instituto.

Um texto seminal na definição de tais diretrizes foi publicado em 1937, quando o autor buscou diferenciar a teoria crítica do que chama de teoria tradicional. Nesse texto, Horkheimer (1975a) questiona a ideia de que o papel de uma teoria seria acumular, a partir da observação do mundo, um saber que permite a descrição minuciosa deste. Para o filósofo, as ciências humanas teriam se orientado pelo modelo das ciências naturais, colecionando evidências e descrevendo a realidade. Nessa abordagem tradicional, o

\footnotetext{
“... trabalho com princípios gerais deve ser considerado ocioso e cômodo [...]. Em vista do quadro atual da pesquisa, o caminho que a sociologia teria que percorrer seria a difícil ascensão da descrição de fenômenos sociais até comparações detalhadas, e só então a partir daí passar para a formação de conceitos gerais" (HORKHEIMER, 1975a, p. 127).
}

Considerando induções como proposições teóricas, o pensamento tradicional realimentaria a ordem existente. Abriria mão, dessa maneira, da dimensão normativa da teoria: "O cientista e sua ciência estão atrelados ao aparelho social, suas realizações constituem um momento de autopreservação e da reprodução contínua do existente, independentemente daquilo que imaginam a respeito disso" (HORKHEIMER, 1975a, p. 131). Tal forma de fazer ciência operaria da mesma maneira que a economia capitalista, naturalizando construções sociais e perpetuando formas de dominação sob a aparência da neutralidade.

\footnotetext{
2 Para ricas apresentações da história do Instituto de Pesquisa Social, ver: Wiggershaus (2002); Jay (1996); Wheatland (2009); Nobre (2004; 2008); Duarte (2002).
} 
A Teoria Crítica, em contrapartida, deveria revisar as próprias categorias do pensamento, compreendendo as ações sociais dentro de seu contexto e atentando para as relações de dominação que a perpassam. Em uma procura pelo resgate da dimensão emancipatória da razão, Horkheimer sugere que a Filosofia e a Ciência Crítica deveriam desnaturalizar o mundo para transformá-lo. O papel da Teoria Crítica seria desvelar o modo como a estrutura social coíbe a autonomia dos sujeitos, revelando chaves conceituais que fomentem a emancipação humana.

A defesa da autodeterminação não implica, contudo, a aceitação do individualismo metodológico. Ao contrário, Horkheimer critica o modelo cartesiano que embasaria o pensamento burguês no qual o ego autônomo "se eleva à condição de causa primeira do mundo ou se considera o próprio mundo" (HORKHEIMER, 1975a, p. 140). Para o autor, o processo de formação da consciência não seria individual, mas da própria humanidade, o que promoveria a transformação social. A saída aberta por Horkheimer passa, assim, por uma revitalização da consciência crítica que permitiria aos seres humanos questionar as práticas que marcam a vida social desde seu interior.

Esse ponto é particularmente importante para entender a Teoria Crítica: a aposta é na procura por instâncias intramundanas de transcendência. Em Horkheimer, a possibilidade de transcendência reside na exposição das contradições de classe. No marxismo do autor, a teoria deveria intensificar a luta de classes, opondo-se aos apologistas do mundo vigente, aos conformistas e aos utópicos, que não compreendem as condições de possibilidade da transformação do mundo. Na leitura de Horkheimer, a reflexão teórica deveria viabilizar, concreta e contextualizadamente, o fim da exploração: "Se o pensamento não se limita a registrar e classificar as categorias da forma mais neutra possível, isto é, não se restringe às categorias indispensáveis à práxis da vida nas formas dadas, surge imediatamente uma resistência" (HORKHEIMER, 1975a, p. 155).

A base da resistência advogada por Horkheimer é um marxismo não ortodoxo em que o âmbito econômico é essencial, embora não seja a única dimensão a ser considerada. "A crítica teórica e prática tem que focalizar inicialmente a causa primeira da miséria, a economia. Mas, julgar também as formas da sociedade futura, baseando-se apenas na sua economia, não seria um pensamento dialético, mas sim mecanicista" (HORKHEIMER, 1975b, p. 166-7).

O marxismo não economicista de Horkheimer fica evidente na Dialética do Esclarecimento, escrita em coautoria com Adorno. Publicada na década de 1940, a obra apresenta uma profunda discussão sobre os efeitos da centralidade da razão na modernidade. O livro aborda o modo como o iluminismo, manifesto não apenas na ciência, mas nas práticas econômicas e culturais, prometeu-nos um mundo controlado e guiado pelos seres humanos, embora tenha conduzido a humanidade à submissão e à perda da capacidade crítica (ADORNo \& HORKHEIMER, 1985). Como explica Duarte, na visão dos autores, "a racionalidade que aprendeu a se empobrecer, a se coisificar, a fim de se tornar instrumento de domínio da natureza, não consegue mais encontrar o seu caminho de volta a si, e a inconsciência, outrora característica apenas da natureza, toma de assalto o âmbito da cultura" (DUARTE, 1997, p. 49-50).

O império da racionalidade instrumental renovaria uma dinâmica presente no mito, ao tentar dominar a realidade por meio da explicação discursiva. No entanto, tal racionalidade teria dado um passo além ao mitificar-se. Explorando a manifestação dessa dialética na literatura, na ciência, na 
filosofia, na indústria cultural e no antissemitismo, Adorno e Horkheimer (1985) evidenciam que a grande esperança emancipatória da humanidade converteu-se em sua maior prisão. Alienação, esvaziamento da linguagem, transformação de meios em fins, conformismo e barbárie seriam frutos do mundo que se supôs esclarecido.

Diante deste cenário, A Dialética do Esclarecimento aposta na própria realização da modernidade, cujo elemento reflexivo poderia fomentar a autonomização da humanidade. Fundamental nesse processo seria uma renovação da linguagem, que evitasse a separação moderna entre os planos semântico e expressivo. Tal distinção teria esvaziado a arte, a ciência e outras práticas comunicativas visceralmente importantes para a transformação do mundo. É essa complexificação da linguagem que Adorno tem em vista ao enfatizar a importância política da estética. Ao superar a clivagem entre o plástico e o significativo, a estética "redialetizaria" a racionalidade (DUARTE, 1997, p. 61).

Mesmo que a primeira geração frankfurtiana tenha sido mais eficiente no diagnóstico crítico das patologias da modernidade, as sementes para pensar a dialética entre opressão e emancipação foram lançadas. É a partir delas que Habermas, expoente da segunda geração de Frankfurt, edifica sua obra, opondo a racionalidade comunicativa à racionalidade instrumental (HABERMAS, 1983; 1987). Também é a partir dessas sementes que Honneth (2003), líder da terceira geração, reinterpreta a obra hegeliana e o papel da psicanálise nas Ciências Sociais para elaborar sua teoria do reconhecimento. Por caminhos distintos e abrindo diálogos específicos, ambos buscaram fazer um diagnóstico de seu tempo para, criticamente, vislumbrar possibilidades emancipatórias viáveis, embora cerceadas.

\section{Deliberação: uma Teoria Crítica?}

Exploradas algumas das definições e dos objetivos que estruturam a Teoria Crítica, faz-se importante, agora, levantar argumentos que indicam hiatos fundamentais entre tal tradição e o modelo deliberacionista. Ainda que haja vários pontos de sobreposição entre esses argumentos, apresentá-los-ei em três eixos distintos.

\section{A deliberação reforça a ordem existente}

O primeiro argumento a ser mencionado encampa autores que afirmam que as premissas básicas da deliberação pública alimentam processos opressivos. Sob a falsa alegação de fomentar a participação, a deliberação legitimaria práticas e procedimentos que contribuem para a manutenção do status quo. Esse argumento está presente desde as primeiras críticas de feministas e democratas da diferença às discussões habermasianas (FRASER, 1999; SANDERS, 1997; YounG, 1996; Mouffe, 2005).

De modo geral, afirma-se que as pressuposições necessárias ao funcionamento da deliberação são marcadas pelo ideário iluminista: a igualdade, a racionalidade, a possibilidade do consenso. Tais pressupostos obliterariam a percepção de desigualdades profundas, ocultando o modo como o consenso racional pode reproduzir anseios de grupos dominantes. 0 modelo deliberacionista, com suas exigências formalistas, mascararia relações de dominação, reforçando-as. Nesses termos, a abordagem deliberativa seria antitética ao ideário crítico: sem revelar as contradições sociais, ela acabaria por fortalecer o mundo vigente, cristalizando visões de mundo e valores opressivos.

A imposição de ideais racionalistas e universalistas daria continuidade ao projeto iluminista, suprimindo o agonismo e cristalizando hegemonias (MOUFFE, 2005). Além disso, o foco na deliberação 
suprimiria diversas modalidades de ação importantes para a transformação do mundo (YOUNG, 2003). Sintetizando os argumentos de democratas da diferença, Pereira explica essa questão:

\footnotetext{
"A excessiva ênfase dada pelos teóricos deliberativos da democracia no consenso e nos espaços de partilha de poder [...] de certa forma acabou por obscurecer outras formas de ação política, tais como manifestações, passeatas, abaixo assinados, invasões e cyberações desenvolvidas por actores da sociedade civil" (PEREIRA, 2010, p. 11).
}

Em grande medida, esses efeitos colaterais do modelo deliberativo dever-se-iam, alegam os críticos, à sua negligência em relação à questão do poder. Ao buscar expandir o conceito de política para além da luta de interesses, os deliberacionistas teriam enfocado a cooperação, esquecendo-se que política é uma questão de interesse e poder (SHAPIRO, 1999). Na opinião de Mouffe:

\footnotetext{
"De acordo com a abordagem deliberativa, quanto mais democrática uma sociedade, menos o poder será constitutivo das relações sociais. Se aceitarmos, contudo, que as relações de poder são constitutivas do social, então a questão principal para a política democrática não é como eliminar o poder, mas como constituir formas de poder mais compatíveis com valores democráticos" (Mouffe, 2005, p. 19).
}

Essa preocupação com a negligência do poder e do conflito é a base dos temores de Luís $\mathrm{F}$. Miguel. Em trabalhos recentes, o pesquisador tem procurado vincular as consequências maléficas da guinada deliberativa a este ponto. Vale citar, aqui, o artigo em que ele discute o conceito de representação, pontuando a "necessidade de recolocar a noção de interesse no centro da nossa compreensão da representação política, bem como de restabelecer o entendimento que a atividade representativa é uma forma de exercício de poder" (MIGUEL, 2010, p. 2).

Para alguns, a falta de uma discussão sobre poder entre os deliberacionistas fomentaria a naturalização das assimetrias. Ao pressupor a igualdade entre os deliberantes, a ideia de força do melhor argumento legitimaria decisões cujas bases residem no poder do interlocutor. É assim que, apesar de suas contribuições, diversos fóruns participativos podem reproduzir as relações assimétricas existentes (CoRnwall \& CoelHo, 2009). Ademais, tais fóruns correm o risco de silenciar atores da sociedade civil, impedindo a expressão de críticas mais contundentes à situação vigente.

Para além da reprodução de assimetrias e do enfraquecimento de atores críticos, outro aspecto que pode evidenciar um hiato entre tais fóruns deliberativos e os pressupostos da Teoria Crítica é a sua crescente mercantilização. Basta lembrar, aqui, que pesquisadores de renome, como James Fishkin e Ned Crosby, patentearam seus desenhos institucionais. Hendriks e Carson (2008) dedicam-se ao estudo deste mercado de consultoria deliberativa que gerou marcas e movimenta, anualmente, milhões de dólares na venda de processos, cursos, softwares e práticas de moderação a governos e organizações políticas.

Se tal processo de mercantilização pode difundir a deliberação, ele também pode encorajar a proliferação de processos que fomentam uma espécie de pseudo-participação discursiva. Frequentemente, ferramentas deliberativas seriam aplicadas de forma descontextualizada, 
comercializando um bem que não deveria operar com a lógica comercial. Além disso, consultores podem buscar dirigir processos em determinadas direções ou mesmo avaliar positivamente processos que fracassaram para garantir a continuidade dos negócios. Afinal, ninguém deseja clientes insatisfeitos. Assim, "a motivação de aprofundamento da democracia está sendo substituída pelos imperativos dos negócios e da competição" (HENDRIKS \& CARSON, 2008, p. 309). As autoras lembram, ainda, que a comercialização da deliberação tende a compatibilizá.la com o sistema capitalista em vigor, afastando o modelo de suas raízes frankfurtianas.

\section{A deliberação conformou-se às instituições liberais e às instituições existentes}

O segundo eixo de distanciamento entre o modelo deliberacionista e o legado crítico não expressa uma desconexão originária entre as duas tradições, mas um progressivo afastamento entre elas. $O$ argumento, aqui, é o de que a democracia deliberativa teria se acomodado às configurações políticas atuais. Embora tenha nascido crítica ao liberalismo, pouco a pouco, a deliberação tê-lo-ia aceitado, justificando as instituições existentes.

Essa crítica emerge de forma contundente na leitura que Dryzek (2000a) faz sobre o desenvolvimento da obra de Habermas. Dryzek aponta que, diferentemente das contribuições críticas desenvolvidas na Teoria da Ação Comunicativa, Habermas teria, paulatinamente, aceitado a democracia liberal tal como ela se encontra institucionalizada. Nessa leitura, Direito e Democracia (1997) defenderia um modelo em que a discussão ocorreria de forma pulverizada e as decisões políticas estariam restritas aos representantes eleitos.

Embora Habermas reconheça o papel da sociedade civil, seu modelo de circulação de poder estaria assentado em uma proposta conservadora ao reduzir a participação popular à formação da opinião pública, o que seria plenamente condizente com abordagens liberais. Ademais, é somente nos momentos de crise que Habermas concede alguma capacidade de influência à sociedade civil. O filósofo não vislumbra uma participação mais efetiva desta ou mesmo experimentos democráticos que redesenhem as relações entre Estados e cidadãos.

O argumento, em suma, é o de que o principal filósofo deliberacionista teria cedido demais ao liberalismo. Habermas aceitaria elementos centrais "do sistema político liberal, tais como eleições, o poder normativo do legislativo e a estrutura administrativa para implementá-Io" (PEREIRA, 2010, p. 10). Para lembrar uma clássica frase de Adorno e Horkheimer (1985), é como se Habermas mudasse a indumentária da sempre semelhante democracia liberal, que legitima diversas formas de opressão do mundo atual.

Dryzek (2000b, p. 80) aponta, ainda, que muitos liberais teriam se declarado deliberacionistas porque os princípios deliberativos ajudam a justificar direitos liberais. Além disso, processos de formação e revisão da constituição são pensados pelos liberais como alicerçados em intercâmbios argumentativos. É isso que teria levado autores como Rawls, Ackerman e Estlund a se interessarem pela deliberação.

No mesmo esteio, Faria tem refletido sobre o processo de aproximação dos deliberacionistas com o liberalismo. De acordo com a pesquisadora, "para acomodar conceitos como autointeresse, poder e conflito e outras formas de comunicação que não só o discurso, mas também a barganha, esta teoria tem se 
distanciado dos pressupostos que a orientava" (FARIA, 2010, p. 1). A busca por um modelo mais realista teria enfraquecido o teor crítico que alicerçava o modelo. Isso seria patente na proposta de sistema deliberativo defendida por Mansbridge (1999; 2007), no modelo integrado de deliberação de Hendriks (2006) e na ideia de um sequenciamento de etapas deliberativas advogada por Goodin (2005).

Transformada em uma prática mais informal, que envolve diferentes modalidades comunicativas e diversas arenas sociais, o "objetivo da deliberação passa a ser [...] clarear o conflito e tentar conformá-lo e, não mais, a busca do consenso em torno do bem-comum" (FARIA, 2010, p. 7). Ao descartar a ideia de bem-comum e atentar para a necessidade de acordos entre posições inconciliáveis, a política voltaria a ser concebida como luta de interesses divergentes. Assim, Faria ressalta que a deliberação tornou-se muito próxima "daquilo que podemos chamar de pluralismo de segunda geração e/ou neo-corporativismo que enfatizam a importância da atividade e da dinâmica de grupos de interesse para a democracia" (FARIA, 2010, p. 14). O giro do giro deliberativo, como o nomeia a pesquisadora, enfraqueceria sua potencialidade crítica, reduzindo o horizonte normativo apregoado pelos deliberacionistas clássicos.

\section{A guinada empírica aproximou a abordagem deliberacionista da teoria tradicional}

O terceiro eixo de distinção entre o viés deliberacionista e a tradição frankfurtiana também está ligado a este giro do giro deliberativo diagnosticado por Faria. No entanto, o foco, aqui, não recai na convergência política entre o pluralismo e o deliberacionismo, mas envolve uma questão epistemológica. Ao operacionalizar-se empiricamente, o modelo deliberacionista não só se tornou mais realista, mas também adotou premissas e estratégias típicas da teoria tradicional.

A guinada empírica da teoria deliberativa nos anos 2000 é marcada por um crescente número de trabalhos dedicados à produção de operadores, escalas, métodos e softwares voltados à análise de processos deliberativos (BLACK et al, 2009; BÄCHTIGER et al, 2009; DRYZEK, 2008; THOMPSON 2008; Stromer-Galley, 2007; Rosenberg, 2005). Tais estudos buscam compreender os padrões de funcionamento da deliberação no mundo real, aplicando o denso quadro normativo deliberacionista ao estudo de práticas diversas.

Ainda que fóruns deliberativos configurem-se como um objeto privilegiado de pesquisa ${ }^{3}$, muitas investigações voltam-se para o estudo de conversações políticas informais ${ }^{4}$, dos meios de comunicação ${ }^{5}$ e de debates parlamentares ${ }^{6}$. A internet, com suas salas de bate-papo, fóruns, blogs e redes sociais, também tem se mostrado um objeto atraente ${ }^{7}$. Black e seus colaboradores (2009) indicam que, entre os métodos mais frequentemente empregados em tais estudos, estão os surveys, as entrevistas, a análise de dados indiretos e a análise de discussão, na qual se inserem análises de conteúdo e de discurso.

Neste artigo, seria impossível fazer um mapeamento detalhado das nuances e idiossincrasias dos diferentes estudos. Gostaria de chamar a atenção, contudo, para um objetivo comum a muitos deles: a mensuração da deliberatividade de fragmentos do tecido social. Grande parte das investigações busca estudar interlocuções ou arenas discursivas específicas a fim de avaliar quão próximas se encontram dos

\footnotetext{
${ }^{3}$ Cf. Cornwall e Coelho (2009); Gastil e Levine (2005); Fung e Wright (2003).

${ }^{4}$ Polletta (2008), Conover \& Searing (2005).

${ }^{5}$ Cf. Wessler (2008), Ettemma (2007), Maia (2008).

${ }^{6}$ Cf. Bächtiger et al (2009), Steenbergen et al (2003).

${ }^{7}$ Cf. Wales et al (2010); Davies \& Gangadharan (2009); Xenos (2008); Graham \& Witschge (2003).
} 
procedimentos deliberativos. Conceitos caros aos deliberacionistas, como inclusão, reciprocidade e publicidade, servem de base à estruturação de livros de códigos para a análise concreta de fenômenos sociais.

Uma metodologia de mensuração de deliberatividade que tem ganhado grande projeção é o Discourse Quality Index (DQI). Desenvolvido por Steenbergen e seus colaboradores (2003) a partir da ética do discurso habermasiana, o instrumento oferece um detalhado livro de códigos para micro. análises comparativas ${ }^{8}$. Outra tentativa interessante de construção de um instrumento de mensuração de deliberatividade foi proposta por Wessler (2008) para a análise de debates políticos nos meios de comunicação. O pesquisador alemão também defende uma abordagem comparativa, voltando-se para a compreensão do impacto de diferentes sistemas de comunicação sobre a deliberação.

Mas como essa guinada empírica pode contribuir para o afastamento da teoria deliberacionista de suas raízes frankfurtianas? Não é meu intuito afirmar que a pesquisa empírica é inviável dentro do marco filosófico crítico. Tampouco ousaria apregoar que o pensamento especulativo pode desprender-se de diagnósticos empiricamente fundamentados. A questão é que a análise de deliberatividade tem se configurado, frequentemente, nos moldes da ciência tradicional.

A preocupação com o método sobrepõe-se, sistematicamente, aos conceitos e problemas de pesquisa. Busca-se mensurar o mundo exaustivamente por meio de modelos estatísticos, a partir dos quais se extraem, por indução, generalizações teóricas sobre o funcionamento da deliberação. Os propósitos dessas mensurações, e mesmo os elementos que as fundamentam, nem sempre são bem delimitados. Eliminam-se atributos importantes, como a sinceridade dos interlocutores, o grau de visibilidade das discussões ${ }^{9}$ e as especificidades culturais de diferentes localidades. Negligencia-se que o que é uma "boa" deliberação pode variar de um contexto para outro ${ }^{10}$. Mensurar processos distintos com categorias pré. definidas pode engessar a análise e negligenciar modalidades deliberativas diversas.

Observa-se que, pouco a pouco, a teoria deliberacionista teria deixado de se configurar como um horizonte normativo que possibilita uma análise crítica do mundo para se transformar em um instrumento de descrição da realidade. 0 foco exclusivo na mensuração de deliberatividade - a obsessão em testar a hipótese da existência da deliberação - tem cerceado a realização de outros tipos de estudos que não buscam descrever o mundo, mas refletir, criticamente, sobre ele. Assim, a guinada empírica alterou não apenas as definições da democracia deliberativa, mas alguns de seus propósitos.

Há que se perceber, ainda, que os resultados dessas investigações parecem alimentar, em alguns casos, a ordem existente. Em primeiro lugar, nota-se que a maioria das pesquisas indicam que o mundo real está aquém dos ideais deliberativos, em um pessimismo esvaziado que alimenta conformismo ou utopia, ambos destituídos de natureza crítica. Em segundo lugar, observam-se os estudos que depositam grande esperança em pequenos fragmentos de deliberatividade, não percebendo muitas das injustiças profundas que marcam as democracias liberais contemporâneas. Em terceiro lugar, vale lembrar, com Hendriks e Carson (2008), que muitos estudos empíricos não estão a serviço do

\footnotetext{
${ }^{8} \mathrm{O}$ DQI tem sido revisado e alterado pelos pesquisadores, como explicitam Bächtiger et al (2009).

${ }^{9}$ Gomes (2008) critica muitos estudos deliberacionistas que se contentam com a mensuração da discutibilidade de fragmentos interacionais sem abordar a visibilidade de tais debates.

${ }^{10} \mathrm{O}$ sarcasmo e a ironia, por exemplo, são mais fortes em algumas culturas e nem sempre indicam desrespeito.
} 
aprofundamento democrático ${ }^{11}$. 0 uso administrativo de tais pesquisas mostra-se fundamental para a manutenção do mercado de processos, consultorias e softwares que tem metas muito mais quantificáveis do que a promoção do debate entre cidadãos. A mercantilização da democracia deliberativa evidencia como essa teoria foi colonizada pela lógica do mercado, contribuindo para a manutenção de práticas opressivas que a Teoria Crítica sempre buscou suprimir.

\section{Entre aproximações e distanciamentos}

Apresentados três eixos argumentativos que reivindicam a existência de um hiato entre teoria deliberacionista e o legado frankfurtiano, faz-se preciso, agora, enfrentar a indagação que move o presente artigo: a democracia deliberativa é uma teoria crítica? Com o perdão da zona de conforto, a resposta é: sim e não. Mantenho o argumento de que há distinções fundamentais entre a abordagem deliberacionista e o pluralismo liberal e reafirmo que a deliberação pode ser eficiente na superação de assimetrias, mas devo reconhecer que a teoria deliberacionista não é inteiramente fiel à tradição crítica.

No que concerne ao primeiro eixo argumentativo sobre a distinção originária entre Democracia Deliberativa e Teoria Crítica, julgo-o, em grande medida, inadequado. 0 modelo deliberacionista de democracia não é contrário ao agonismo, nem fecha os olhos para as profundas assimetrias que marcam as comunidades políticas (MANSBRIDGe et al, 2010; DRYZeK \& NiemeYer, 2006; BOHMAN, 1996). Interesse e poder são conceitos úteis à matriz deliberacionista, ajudando a descortinar práticas opressivas e a refletir sobre a possibilidade de superação delas. Aliás, o foco no debate argumentativo implica o reconhecimento de que os jogos de força existentes não devem ditar o rumo das decisões, o que ocorre, por definição, nas barganhas do liberalismo pluralista.

Desse modo, não é paradoxal falar em negociações deliberativas. A questão é que tais negociações devem ser não-coercitivas (MANSBRIDGE et al, 2010). $O$ autointeresse tampouco precisa ser deixado de lado nessa teoria, como o evidenciam, coletivamente, alguns dos expoentes do modelo: "qualquer ideal do político, de democracia legítima e de democracia deliberativa deve incluir o autointeresse e conflitos entre interesses de modo a reconhecer e celebrar, no ideal em si mesmo, a diversidade de seres humanos livres e iguais" (MANSBRIDGE et al, 2010, p. 69). De acordo com eles, o autointeresse é importante para a deliberação tanto porque provê informações sobre o bem-comum e sobre o conflito em questão, como porque alimenta diversas formas frutíferas de acordo. A "asserção e busca do autointeresse é, em muitos casos, necessária para construir uma negociação justa e plenamente cooperativa" (MANSBRIDGE et al, 2010, p. 75).

É exatamente esse reconhecimento do poder e do interesse que abre o segundo eixo argumentativo exposto no presente artigo. É curioso que alguns autores que salientam a progressiva aproximação entre deliberacionistas e neopluralistas reconheçam que a preocupação com a dimensão do poder já estava dada nas discussões originais de Habermas (FARIA, 2010). Nesse sentido, o giro do giro parece conduzir, como o próprio nome sugere, ao ponto de partida, sem que se note uma alteração profunda nas premissas trabalhadas. Ao salientar a questão do poder e do interesse, os deliberacionistas não se distanciam de seus alicerces, mas parecem clareá-lo.

\footnotetext{
${ }^{11}$ Não me refiro, aqui, às pesquisas de Steenbergen et al (2003) e de Wessler (2008).
} 
Com isso, não quero dizer que a deliberação sempre foi um nome sofisticado para a defesa do pluralismo liberal. Ao contrário, reafirmo que a deliberação foi (e continua a ser) distinta dele. A diferença básica entre as duas abordagens reside na compreensão dos atores políticos e da formação dos interesses. Fundada na ação comunicativa habermasiana, a abordagem deliberacionista questiona a filosofia da consciência e o individualismo metodológico, que são essenciais ao liberalismo. Como percebe Rosenberg, para um importante conjunto de deliberacionistas, o pensamento não é uma atividade que se processa na mente do indivíduo, mas algo que emerge da "interação entre vários sujeitos e das conexões estabelecidas no percurso dessa afetação recíproca" (ROSENBERG, 2007, p. 12). A premissa do modelo deliberacionista é a de que as preferências e os interesses dos atores são continuamente alterados na medida em que se veem atravessados ou confrontados por outros discursos. Por isso, a política não se reduz à competição de preferências. A política brota da própria construção intersubjetiva dos sujeitos e de suas preferências.

Isso não significa que todos os atores sociais sejam gentis e benevolentes a ponto de abrir mão de seus interesses ${ }^{12}$. A questão é que os próprios sujeitos são entendidos como produtos de uma intersubjetividade fundante, que é discursivamente atualizada. Interesses e preferências não são simplesmente expressos para que alguma instância mediadora busque conciliá-los publicamente. Sem deixar de ser agonística, a esfera pública deliberativa não se restringe a um espaço de choque entre preferências pré-estabelecidas. Sua função é mais estrutural e envolve a própria formação de valores, preferências e atores sociais. Essa é uma diferença fundamental em relação à teoria pluralista.

Nesse sentido, o reconhecimento de que diferentes formatos comunicacionais podem ser úteis à deliberação, bem como a defesa de que processos deliberativos podem ocorrer de forma dispersa no tempo e no espaço, não significa uma concessão ao liberalismo. Essa adaptação da comunicação a contextos específicos de enunciação não leva, necessariamente, a uma perda da dimensão crítica. A construção de uma teoria atenta ao contexto em que opera é premissa essencial da tradição crítica que nunca se propôs a projetar horizontes normativos irrealizáveis. É exatamente por isso que Habermas (1997) faz questão de salientar a riqueza da tensão entre a normatividade e a facticidade. 0 que se nota é uma aproximação com o pragmatismo filosófico que, aliás, tem ajudado a revitalizar o legado frankfurtiano.

Por outro lado, e ainda no que concerne ao segundo eixo argumentativo explorado neste artigo, é preciso ter cautela com a disposição de alguns deliberacionistas para acatar as instituições liberais. A falta de imaginação política pode levar a uma aceitação da democracia como ela se encontra, em evidente contradição com a tradição crítica. A estruturação de um mundo mais justo e menos opressivo requer a reflexão constante sobre os formatos institucionais mais adequados à garantia da participação coletiva, bem como sobre o sistema político-econômico que os envolve.

Nessa mesma linha, é preciso ter cuidado com estudos que ressaltam que a deliberação pública já existe de uma forma dispersa em fragmentos midiáticos. Não se deve perder de vista que Habermas (1983; 1997; 2006) manteve uma visão ambivalente em relação aos media, apontando diversos constrangimentos que bloqueiam as promessas tecnológicas. Estudos que ressaltam a potencialidade deliberativa dos media descortinam pontos interessantes do funcionamento democrático, mas não devem ser usados para justificar a ordem existente e restringir a transformação social.

\footnotetext{
${ }^{12}$ A esse respeito, ver Mendonça e Santos (2009).
} 
Se, de fato, a tendência de alguns pesquisadores em aceitar a democracia existente evidencia uma perda do teor crítico, isso não é consequência imediata e necessária da matriz teórica sob análise. Tanto que Dryzek consegue distinguir, no interior da família deliberacionista, uma abordagem liberal e uma abordagem crítico-discursiva:

"É importante resistir à assimilação da democracia deliberativa ao constitucionalismo liberal e recuperar a democracia discursiva como uma alternativa que é mais insistentemente crítica não apenas às constituições liberais, mas, sobretudo, às estruturas do Estado e à economia política de que tais constituições fazem parte" (DRYZEK, 2000b, p.81).

Para manter a abordagem deliberacionista vinculada ao legado crítico, seria essencial submetê. la ao processo dialético, prescrito por Horkheimer. Essa redialetização da teoria deliberacionista depende, em grande medida, da consolidação de novas diretrizes empíricas. A acomodação de alguns deliberacionistas ao liberalismo caminha de mãos dadas com a tendência de realização de pesquisas administrativas, cujo objetivo é mensurar a deliberatividade de fragmentos de realidade. É, pois, nesse terceiro eixo que nota-se o distanciamento mais profundo da abordagem deliberacionista em relação à tradição crítica. Curiosamente, trata-se do eixo menos discutido pelos críticos da deliberação, que parecem aceitar a acomodação deliberacionista aos surveys e métricas da ciência tradicional.

Para evitar erros de interpretação, faço questão de reiterar que o problema não é a pesquisa empírica em si. O ponto, repito, são as premissas epistemológicas que vêm marcando as investigações. O foco na descrição e na mensuração do mundo opera com um paradigma pouco frutífero para a realização dos ideais frankfurtianos. A acomodação de pesquisadores deliberacionistas à matriz positivista não engendra um giro do giro, mas uma virada unilateral que dificulta a leitura crítica do mundo e a reflexão em torno de possibilidades emancipatórias.

A dimensão epistemológica é fundante da Teoria Crítica. Nesse sentido, ressalto a riqueza da utilização da teoria deliberacionista não como uma hipótese a ser confrontada com a deliberatividade do mundo, mas como uma matriz teórica complexa para a reflexão sobre fenômenos sociais e para a proposição de uma renovação do funcionamento da democracia. Matriz esta que ajuda a criticar as relações de poder existentes e a pensar as condições para a superação da opressão. Argumento, assim, que o revigoramento da agenda de pesquisa nessa área, com a alteração de objetivos e métodos, pode reconectar a teoria deliberacionista ao legado frankfurtiano, contribuindo para a sua permanente renovação.

Essa reconexão implicaria um diálogo mais estável entre as tradições. A instabilidade da relação entre a teoria deliberacionista e a herança crítica advém das várias dimensões de aproximação e distanciamento entre elas. Meu argumento é que uma operacionalização metodológica distinta da abordagem deliberativa solidificaria o laço original entre as tradições, fomentando uma teoria democrática normativamente radical, capaz de impulsionar uma agenda política emancipatória.

A proficuidade desse diálogo mais estável está relacionada à possibilidade de uma mútua revisão, que, simultaneamente: 1 ) democratize a Teoria Crítica; e 2) ressalte a dimensão contestatória de 
um debate público que toma corpo em práticas comunicativas diversas. A crítica recíproca entre deliberação e Teoria Crítica possibilita o deslocamento das fronteiras de ambas, ressignificando-as.

0 primeiro aspecto supramencionado se liga às contribuições que a teoria deliberativa traz à tradição frankfurtiana. A primeira geração da escola não possuía uma clara teoria democrática, mesmo porque era extremamente cética em relação às instituições liberal-burguesas das democracias da primeira metade do século XX. Embora defendesse a centralidade da liberdade e da autodeterminação, muitos frankfurtianos da primeira geração foram acusados de certo elitismo que se contrapunha ao igualitarismo marxista que advogavam. A guinada proposta por Habermas, da qual se origina o deliberacionismo, cria as bases para a estruturação de uma teoria democrática consistente e coerente, que abre novas agendas para a Teoria Crítica. Agendas essas que tornaram a Teoria Crítica uma ferramenta mais útil para a compreensão dos fenômenos políticos do final do século XX, e para a proposição da emancipação possível nesse cenário. A crescente atenção de deliberacionistas críticos à transnacionalização da democracia é uma ilustração nesse sentido, como evidenciam trabalhos do próprio Habermas (2001), de Dryzek (2006) e de Bohman (2007).

0 segundo aspecto diz respeito à manutenção da dimensão radicalmente contestatória da teoria deliberacionista de democracia, que não nasceu como abordagem para descrever as instituições democráticas existentes, mas como perspectiva normativa que nunca se quis utópica. O legado crítico é a base da vitalidade emancipatória de que depende a normatividade deliberativa. Isso porque impulsiona a revisibilidade interna da própria teoria deliberativa, levando-a a repensar alguns de seus elementos essenciais. Nota-se, nesse sentido, toda uma literatura recente que tem mostrado a crescente preocupação de deliberacionistas em pensar aspectos fundamentais para a conformação de um viés capaz de questionar as opressões estruturais do mundo contemporâneo.

Ressalta-se, aqui, a maior atenção ao papel democrático das emoções (MANSBRIDGE, 1999; Dryzek, 2000a; DahlBerg, 2005; PARKInson, 2006; Thompson, 2008; MendonçA, 2011). Deliberacionistas têm salientado a centralidade das paixões nas lutas de atores críticos e sua consequente relevância na propulsão da democracia deliberativa (YoUnG, 2000; MedEARIS, 2004; MANSBRIDGE et al, 2010). Também merece destaque a pluralização das formas comunicativas aceitas pelos deliberacionistas, o que foi essencial para a democratização da própria teoria. Young (1996) foi a precursora desse movimento, ao chamar a atenção para a importância de narrativas, cumprimentos e retórica. Logo, tal ideia viu-se amplificada com alguns estudos empíricos sobre testemunhos, como o de Black (2008), e com o aprofundamento da discussão sobre retórica, que marca uma aproximação dos deliberacionistas a Aristóteles (DRYZEK, 2010; CHAMBERS, 2009). Chambers (2009), particularmente, faz questão de enfatizar como essa reaproximação com a retórica é essencial para que a teoria deliberacionista mantenha-se crítica, já que o foco específico no desenho de microinstituições deliberativas ou no teste da deliberatividade não daria conta de gerar os debates efetivamente públicos necessários à emancipação de sociedades complexas.

Obviamente, tais exemplos não visam esgotar a discussão dos recentes rumos da teoria deliberacionista. Meu intuito foi chamar a atenção para a proficuidade de um diálogo estável entre Teoria Crítica e deliberação, que fomente a elaboração de uma teoria democrática radicalmente preocupada com a construção de um mundo mais justo. As correções mútuas entre ambas as perspectivas teóricas e 
a construção de operacionalizações empíricas atentas a essas correções têm, pois, relevância não apenas científica, mas também política.

\section{Referências Bibliográficas}

Adorno, T. W.; Horkheimer, M. Dialética do esclarecimento: fragmentos filosóficos. Rio de Janeiro: J. Zahar Editor, 1985.

BACHTIGer, A.; ShIKANo, S.; PedrinI, S.; Ryser, M. "Measuring Deliberation 2.0: Standards, Discourse Types, and Sequenzialization". Trabalho apresentado em ECPR General Conference. Potsdam, 5-12 Sept. 2009.

Black, L. W. "Deliberation, Storytelling, and Dialogic Moments". Communication Theory, vol. 18, n 1, p. 93-116, Feb. 2008.

.; URKhalter, S.; Gastil, J.; Stromer-Galley, J. "Methods for Analyzing and Measuring Group Deliberation". In: Holbert, L. (Ed.). Sourcebook of Political Communication Research: Methods, Measures, and Analytical Techniques. New York: Routledge, 2009.

BOHMAn, J. Deliberation: pluralism, complexity and democracy. Cambridge: MIT, 1996.

Democracy across borders: from Dêmos to Dêmoi. Cambridge: The MIT Press, 2007.

CARnaÚBA, M. E. C. "Sobre a distinção entre teoria tradicional e teoria crítica em Max Horkheimer". Kínesis, II (03), p. $195 \cdot 204,2010$.

Chambers, S. "Rhetoric and the Public Sphere: has deliberative democracy abandoned mass democracy?" Political Theory, vol. 37, n 3, p. 323.350, 2009.

Conover, P. J; Searing, D. D. "Studying 'Everyday Political Talk' in the Deliberative System". Acta Politica, International Journal of Political Science, vol. 40, n³ 3. p. 269.283, 2005.

Cornwall, A.; Coelho, V. S. Novos espaços democráticos: perspectivas internacionais. São Paulo: Editora Singular, 2009.

DAHLBERG, L. "The habermasian public sphere: taking difference seriously?" Theory and Society, vol. 34, $n^{\circ} 2$, p. 111 . 136,2005

Davies, T; Gangadhran, S. P. (Orgs.). Online Deliberation: Design, Research, and Practice. Chicago: University of Chicago Press, 2009

DEAN, J. "Why the net is not a public sphere". Constellations, vol. 10, n 1, p. 95-112, 2003.

DrYZek, J. S. Deliberative Democracy and Beyond: liberals, critics, contestations. New York: Oxford University Press, 2000a.

Discursive democracy vs. liberal constitutionalism. In: SAWARD, M. (ed.). Democratic innovation. Londres: Routledge, p. 78-89, 2000b.

Deliberative Global Politics: Discourse and democracy in a divided world. Cambridge: Polity Press, 2006.

"The empirical turn in deliberative democracy". Trabalho apresentado em Theory and practice of deliberative democracy workshop, ANU, Canberra, 7.8 fev. 2008.

"Rhetoric in Democracy: A Systemic Appreciation". Political Theory, vol. 38, n 3, p. 319.339, 2010.

.; NIEMEYer, S. "Reconciling pluralism and consensus as political ideals". American Journal of Political Science, vol. 50, n 3 , p. 634.649, 2006.

DuARTE, R. Adornos: nove ensaios sobre o filósofo frankfurtiano. Belo Horizonte: Ed. UFMG, 1997.

Adorno/Horkheimer \& A Dialética do Esclarecimento. RJ: Jorge Zahar, 2002.

EtTEmA, J. S. "Journalism as reason-giving: deliberative democracy, institutional accountability, and the News Media's Mission". Political Communication, vol. 24, n², p. 143-160, 2007. 
FARIA, C. F. "Do ideal ao real: as consequências das mudanças conceituais na teoria da democracia deliberativa". $7^{\circ}$ Encontro da ABCP, Recife, 4 - 7 ago. 2010.

FRASER, N. Rethinking the Public Sphere: a contribution to the critique of actually existing democracy. In: DURING, S. (ed.). The Cultural Studies Reader. Londres: Routledge, p. 518-536, 1999.

Fung, A; Wright, E. (eds.). Deepening Democracy. Londres/NY: Verso, 2003.

GASTIL, J; LEVINE, P. (eds.). The deliberative democracy handbook: strategies for effective civic engagement in the twenty-first century. San Francisco: Jossey-Bass, 2005.

Gomes, W. Esfera Pública Política e Comunicação em Direito e Democracia de Jürgen Habermas. In: Gomes, W.; MAIA, R (eds.). Comunicação e Democracia. SP: Paulus, p. 69.115, 2008.

Goodın, R. E. "Sequencing Deliberative Moments". Acta Politica, International Journal of Political Science, vol. 40, $n^{\circ} 2$, p. $182 \cdot 196,2005$

GRAhAm, T; WITSCHGE, T. "In search of online deliberation: Towards a new method for examining the quality of online discussions". Communications, vol. 28, n², p. 173-204, 2003.

HABERMAS, J. The Theory of Communicative Action, Volume 1: Reason and the rationalization of society. Boston: Beacon Press, 1983.

The Theory of Communicative Action, Volume 2: Lifeworld and system - a critique of functionalist reason. Boston: Beacon Press, 1987.

Direito e Democracia: entre a facticidade e a validade. Rio de Janeiro: Tempo Brasileiro, 1997.

. A constelação pós-nacional. São Paulo: Littera Mundi, 2001.

"Political Communication in Media Society: Does Democracy Still Enjoy an Epistemic Dimension? The Impact of Normative Theory on Empirical Research". Communication Theory, vol. 16, n 4, p. 411.426, 2006.

HendRIKS, C. M. “Integrated Deliberation: Reconciling Civil Society's Dual Role in Deliberative Democracy". Political Studies, vol. 54, n³, p. 486-508, 2006.

$\therefore$ CARSON, L. "Can the market help the forum? Negotiating the commercialisation of deliberative democracy". Policy Sciences, vol. 41, nº 4, p. 293.313, 2008.

Honneth, A. Luta por reconhecimento: a gramática moral dos conflitos sociais. São Paulo: Ed. 34, p. 7-19, 2003.

Horkheimer, M. "Teoria Tradicional e Teoria Crítica”. In: Coleção Os pensadores. São Paulo: Abril Cultural, p. 125-162, 1975 .

“Filosofia e Teoria Crítica". In: Coleção Os pensadores. São Paulo: Abril Cultural, p. 163·169, 1975b.

JAY, M. The dialectical imagination: a history of the Frankfurt School and the Institute of Social Research 1923-1950. Berkeley: University of California Press, 1996.

MAIA, R. C. M. (org.). Mídia e Deliberação. Rio de Janeiro: Editora FGV, 2008.

MANSBRIDGE, J. Everyday Talk in Deliberative System. In: MACEDo, S. (ed.). Deliberative Politics: essays on democracy and disagreement. NY: Oxford University Press, p. 211-239. 1999.

"Deliberative Democracy or Democratic Deliberation?" In: RoSENBERG, S. (org.). Deliberation, participation and democracy. can the people govern? NY: Palgrave, p. 251-271, 2007.

:; Bohman, J.; Chambers, S.; Estlund, D; Follesdal, A.; Fung, A.; Lafont, C.; Manin, B.; Marti, J.L. "The place of self-interest and the role of power in deliberative democracy". Journal of Political Philosophy, vol. 18, n 1, p. 64-100, 2010.

MedeARIS, J. "Social movements and deliberative democratic theory". British Journal of Political Science, 35, p. 53.75, 2004.

MendonçA, R. F. "Reconhecimento e (qual?) deliberação". Opinião Pública, vol. 17, n 1, p. 206-227, 2011.

.; SANTOS, D. B. "A cooperação na deliberação pública: um estudo de caso sobre o referendo acerca da proibição da comercialização de armas de fogo no Brasil”. DADOS - Revista de Ciências Sociais, vol. 52, $\mathrm{n}^{\circ} 2$, p. $507 \cdot 542,2009$. 
Miguel, L. F. "Representação e interesses: uma crítica a Young e Urbinati”. 70 Encontro da ABCP, Recife, 4-7 ago. 2010.

Mouffe, C. "Por um modelo agonístico de democracia". Revista de Sociologia e Política, vol. 25, p. 11-23, 2005.

Nobre, M. Apresentação. In: Honneth, A. Luta por reconhecimento: a gramática moral dos conflitos sociais. São Paulo: Ed. 34, p. 7-19, 2003.

A Teoria Crítica. Rio de Janeiro: Jorge Zahar, 2004.

Curso Livre de Teoria Crítica. Campinas: Papirus, 2008.

PARKInSon, J. Deliberating in the Real World: Problems of Legitimacy in Deliberative Democracy. Oxford: Oxford University Press, 2006.

PereIRA, M. A. "Movimentos sociais e democracia: a tensão necessária". Texto apresentado no V. Congresso Latino Americano de Ciência Política, Buenos Aires, 28-30 jul. 2010.

PollettA, F. “Just Talk: Public Deliberation after 9/11". Journal of Public Deliberation, vol. 4, n 1, p. 1.22, 2008.

Rosenberg, S. "The Empirical Study of Deliberative Democracy: Setting a Research Agenda". Acta Politica, International Journal of Political Science, vol. 40, n², p. 212.224, 2005.

An introduction: Theoretical perspectives and empirical research on deliberative democracy. In:

Deliberation, participation and democracy. can the people govern? New York: Palgrave MacMillan, p. 1.25,

2007

SANDERS, L. "Against Deliberation". Political Theory, vol. 25, n³ 3, p. 347-376, 1997.

SHAPIRO, I. Enough of deliberation: Politics is about interests and power. In: MACEDO, S. (ed.). Deliberative Politics: essays on democracy and disagreement. Nova York / Oxford: Oxford University Press, p. 28-38, 1999.

Steendergen, M. R.; BÄChtiger, A.; SPÖRndli, M.; Steiner, J. "Measuring deliberation: a discourse quality index". Comparative European Politics, vol. 1, $\mathrm{n}^{\circ} 1$, p. 21.48, 2003.

Stromer-Galley, J. “Measuring Deliberation's Content: A Coding Scheme”. Journal of Public Deliberation, vol. 3, $n^{\circ} 1$, p. $1 \cdot 35,2007$

Thompson, D. "Deliberative Democratic Theory and Empirical Political Science". Annual Review of Political Science, 11, p. $497-520,2008$

Wales, C.; CotTeriLl, S.; Smith, G. "Do citizens 'deliberate' in on-line discussion forums? Preliminary findings from an internet experiment”. 60th Political Studies Association Conference, Edinburgh, 2010.

WESSLER, H. "Investigating deliberativeness comparatively". Political Communication, vol. 25, n 1, p. 1-22, 2008.

WheAtLAND, T. The Frankfurt School in Exile. Minneapolis: University of Minnesota Press, 2009.

Wiggershaus, R. A Escola de Frankfurt. História, desenvolvimento teórico, significação política. Rio de Janeiro: DIFEL, 2002

XENOS, S. "New mediated deliberation? Blog and press coverage of the Alito nomination". Journal of Computer-mediated communication, vol. 13. $n^{\circ} 2$, p. 485-503, 2008.

YounG, I. Communication and the Other: beyond deliberative democracy. In: BeBHABIB, S. (ed.). Democracy and difference: contesting the boundaries of the political. Princeton: Princeton University Press, p. 120-135, 1996.

Inclusion and Democracy. Oxford: Oxford University Press, 2000.

Activist Challenges to deliberative democracy. In: FISHKIN, J.; LASLETT, P. (eds.). Debating deliberative democracy. Malden: Blackwell, p. 102-120, 2003.

Ricardo Fabrino Mendonça -ricardofabrino@fafich.ufmg.br

Submetido à publicação em março de 2012. Aprovado para publicação em junho de 2012 